\title{
Entre o discurso e a prática: o lugar da pesquisa na formação de professores
}

Luciana Aparecida de Araujo Penitente ucianapenitente@gmail.com 0000-0003-1147-5039

Faculdade de Filosofia e Ciências da Universidade Estadual Paulista Unesp, Campus de Marília.

Claudia Regina Mosca Giroto claudia.mosca@marilia.unesp.br 0000-0001-6267-8085

Faculdade de Filosofia e Ciências da Universidade Estadual Paulista Unesp, Campus de Marília e

Faculdade de Ciências e Letras, Unesp, Campus de Araraquara.

Altair Borges de Souza altair.borges@bol.com.br 0000-0003-0801-4418

Faculdade de Filosofia e Ciências da Universidade Estadual Paulista -

Unesp, Campus de Marília.

\section{RESUMO}

Entre os diversos aspectos que perpassam a discussão em torno da formação de professores destacamos o papel da pesquisa como componente relevante no âmbito educacional e necessário no processo formativo desses profissionais. O estudo em questão, de natureza documental e de campo, teve por objetivo investigar a compreensão de formadores que atuam no ensino superior sobre a importância da pesquisa na formação inicial de professores. Para a coleta dos dados utilizamos depoimentos orais de 14 professores de um curso de pedagogia, bem como análise documental, que incluiu o projeto político pedagógico desse curso e 22 planos de ensino disponibilizados no formato de domínio público. Foi possível evidenciar incongruências nas políticas de pesquisa da instituição que oferece o curso em questão, no que diz respeito, particularmente, à compreensão reducionista sobre pesquisa e às práticas propostas para a atuação docente com esse tema nas disciplinas ministradas, restritas à utilização de algumas técnicas de coleta de dados.

PALAVRAS-CHAVE: Educação. Formação de professores. Pesquisa. 


\section{INTRODUÇÃO}

A pesquisa como elemento significativo para a atividade profissional dos professores tem sido muito discutida no cotidiano de formadores de professores bem como é tema presente na legislação (BRASIL, 1996; 2002; 2006; 2013; TARDIF; ZOURHLAL, 2005; LÜDKE; CRUZ, 2005; DINIZ-PEREIRA, 2006; RIBEIRO; GUEDES, 2007; ABREU; ALMEIDA, 2008; PESCE; ANDRÉ, 2012; PENITENTE; 2012; CORREIA; RIBEIRO, 2013).

Dentre os diversos aspectos que perpassam tal discussão, destaca-se um grande dilema: de um lado, encontramos a necessidade de formar profissionais de educação capazes de levantar questões e buscar respostas teóricas e práticas para os desafios e necessidades do cotidiano escolar e, por outro, constatamos que os cursos de licenciatura nem sempre oferecem respostas adequadas, tanto em termos de sua organização curricular, quanto em relação às práticas pedagógicas que capacitem o profissional no cumprimento de suas funções.

Entendemos que o professor que vivenciou atividades de investigação em sua formação inicial, independentemente de sua escolha profissional, tenderá a assumir uma postura diferente em sala de aula, sendo mais propenso a tornar-se sujeito ativo, crítico, participativo, autor de sua prática, que busca novos conhecimentos e novos caminhos. Capaz de problematizar a ação docente, selecionar técnicas de coleta de dados, analisar sua prática docente em relação ao contexto no qual atua e, a partir da compreensão dos problemas estudados, traçar caminhos alternativos para sua prática. Neste sentido, a pesquisa é aqui compreendida não apenas como busca de conhecimento, mas, como postura política que deverá ser assumida pelo sujeito e poderá levar a sua emancipação social.

Acreditamos que a pesquisa no âmbito educacional e a construção do espírito investigativo do professor precisa ser uma preocupação e postura adotada nos cursos de formação de professores, bem como o ensino deve ocorrer por meio de efetivas práticas de construção do conhecimento. Assume relevância, portanto, a temática ora enfatizada, frente à necessidade de compreensão do papel da pesquisa na formação do professor.

A Lei de Diretrizes e Bases da Educação Nacional, a LDBEN (BRASIL, 1996; 2013), desencadeou um amplo processo de revisão e reorganização das propostas curriculares para os cursos de graduação, em especial os de formação de professores. Daí decorreu, entre 2001 e 2005, um intenso processo de elaboração das Diretrizes Curriculares Nacionais para a Formação de Professores para a Educação Básica (BRASIL, 2002) e para o Curso de Pedagogia (BRASIL, 2006), que deu origem a uma diversidade de posições e propostas defendidas pelas universidades e pesquisadores preocupados com a melhoria da qualidade do ensino destinado à formação do professor (RIBEIRO; GUEDES, 2007).

Devido à sua concepção, os cursos de licenciatura têm sido alvo de intensos debates no cenário educacional, principalmente no que diz respeito à estrutura $3+1$, que acaba reforçando o predomínio da formação dos conteúdos sobre a formação pedagógica. Essa distância entre a formação teórica e a prática é justificada porque se acredita que as ações do professor podem ser garantidas pela teoria, bastando apenas a sua aplicação. A "crise de identidade" também é outro problema enfrentado pelas licenciaturas em Pedagogia, como decorrência 
da indefinição da atual legislação e da criação de novas instituições de formação de professores, a exemplo do curso normal superior e dos institutos superiores de educação. A preparação para a pesquisa e a formação do futuro pesquisador continuam a ser associadas, nas diferentes áreas do conhecimento, a cursos de bacharelado e feitas em detrimento dos cursos de licenciatura (LÜDKE; CRUZ, 2005).

A virada da década de 1980 para a de 1990 foi marcada pela "[...] crise de paradigmas". Nesse contexto, o pensamento educacional brasileiro e os estudos sobre os saberes necessários a formação de professores voltaram-se, sobretudo, para a compreensão dos aspectos microssociais das atividades educativas destacando, sob novos prismas, o papel do agente-sujeito. Passou-se a valorizar a figura do professor-pesquisador, conferindo importância à formação do profissional reflexivo, cuja atividade profissional está atrelada à atividade de pesquisa (DINIZ-PEREIRA, 2006, p. 41).

Acreditamos, contudo, que é necessário precisar o cerne do trabalho de pesquisa a ser desenvolvido com professores em processo de formação inicial. Este, a nosso ver, deve contribuir para desenvolver no futuro professor o espírito científico e as atitudes para a investigação com base em conhecimentos epistemológicos e metodológicos que norteiam suas atividades de pesquisa, como exercício didático em que o futuro professor tenha condições de fazer escolhas teóricas e metodológicas diante dos impasses que o cotidiano coloca para a prática pedagógica.

Com o intuito de articular teoria e prática pedagógica, pesquisa e ensino, reflexão e ação didática surge a defesa do "[...] professor com espírito investigador" (DINIZ-PEREIRA, 2006, p. 44). Assim, acredita-se na necessidade de fomentar no futuro professor o espírito investigativo, ou seja, atitudes e habilidades para a investigação com base em um conhecimento teórico-prático, enfatizando a necessidade de conhecimentos epistemológicos e metodológicos que norteiam as atividades de investigação.

Gatti (2007, p. 63), por sua vez, enfatiza que o "[...] desenvolvimento de habilidades para a pesquisa só se faz no próprio trabalho de pesquisa". Essa posição é corroborada por Tardif e Zourhlal (2005), ao chamarem a atenção para o fato de que os programas de formação inicial de professores são pouco eficientes para prepará-los para a leitura e compreensão dos discursos da pesquisa. Para esses autores, a formação em pesquisa dos futuros professores e dos professores que já estão em serviço deveria ocupar mais espaço nos programas acadêmicos e iniciar os alunos nas pesquisas contemporâneas sobre o ensino, não apenas em questões metodológicas.

Lüdke e Cruz (2005), ao discutirem essa temática, num estudo realizado com a participação de formadores de professores de cursos de licenciatura de duas universidades públicas do Rio de Janeiro, por meio da utilização de entrevista, constataram que, embora esses formadores de professores reconheceram a importância da pesquisa na formação dos futuros professores, consideraram que ainda falta espaço para a pesquisa na organização curricular dos cursos de formação inicial, fato revelador de uma concepção culturalmente arraigada na história dos cursos de licenciatura que separa a formação de bacharéis e licenciandos, vinculando a pesquisa aos primeiros. Para essas autoras, a importância e a necessidade da pesquisa na escola básica vieram acompanhadas, 
na maioria das vezes, de um discurso que associa a relação entre formação inicial e prática docente. Destacaram ter sido consenso entre os entrevistados que a pesquisa é importante e necessária para dar conta da atualização profissional dos professores. No entanto, sua formação inicial isolada não é suficiente para a constituição de um profissional que esteja preparado para os reais desafios da escola básica.

É sabido que o conhecimento didático não conseguirá abranger tudo o que pode ocorrer durante o ensino e a aprendizagem do aluno e a pesquisa como exercício didático pode se constituir como elemento a mais na construção da autonomia dos alunos-professores.

Lerner e Sadovski (1996) afirmam, entretanto, que é preciso compreender as variáveis que estão implicadas na situação didática. Os resultados alcançados mediante pesquisa não devem servir como receituários, mas favorecer efetivas situações de aprendizagem.

A simples existência da pesquisa no cotidiano dos cursos como realidade a ser vivida pelos alunos propõe um novo sentido no contexto acadêmico: colocar os futuros professores frente à questão do conhecimento como resultado de um processo de autoria que os retira do lugar de objetos e os convoca a assumirem a responsabilidade de fazerem-se sujeitos (ROSA; CARDIERI; TAURINO, 2008).

Diante dos limites impostos aos cursos de Licenciatura para formar o professor, ao vivenciar atividades de investigação e de pesquisa na graduação esse profissional tem a possibilidade de assumir atitudes diferenciadas em sua prática. Não se espera, com isso, formar o professor pesquisador, mas oferecer a possibilidade de fomentar no aluno o interesse pela pesquisa, de maneira que possa representar uma ferramenta a mais na formação do futuro professor, possibilitando o exercício de uma atividade criativa e crítica, subsidiada pelo questionamento e busca de alternativas para a solução dos problemas investigados.

Diagnosticar, levantar hipóteses, buscar fundamentação teórica e realizar procedimentos de análise de dados são atividades que podem auxiliar o trabalho docente. Dessa forma, se faz necessário que esse fomento investigativo seja estimulado já na formação inicial do aluno, independentemente se ele vai desenvolver atividade científica ou não (LÜDKE, 2002; 2012). Nessa perspectiva, Pesce e André (2012, p. 43) afirmam que a pesquisa pode proporcionar "[...] mudanças na visão de mundo dos estudantes iniciantes, já que é uma atividade problematizadora da realidade, o que pode levá-los a se engajarem em projetos de uma sociedade mais justa e menos desigual".

Para Diniz-Pereira e Lacerda (2009, p. 1234) a atividade investigativa favorece a articulação tanto de processos cognitivos, quanto linguísticos, criativos e dialógicos, pois interfere na formulação de saberes específicos da prática docente e na compreensão do contexto educacional em que se situam. Do ponto de vista político poderá contribuir para o rompimento de saberes e práticas de poder. 
Frente a essas ideias, este estudo teve por objetivo investigar a compreensão de formadores que atuam no ensino superior sobre a importância da pesquisa na formação inicial de professores.

\section{PERCURSO METODOLÓGICO}

Com o desafio de estabelecer reflexões necessárias entre o ensino da pesquisa na formação inicial do professor e as teorizações de pesquisadores, cujos estudos têm constituído este campo de saber, a investigação ora relatada, que compreendeu tanto pesquisa documental, quanto pesquisa de campo, priorizou parte dos dados resultantes de pesquisa aprovada pelo Comitê de Ética, sob o parecer no 83/2011, em 24/08/2011.

A pesquisa de campo se configurou por depoimentos orais de 14 professores, que atuam num curso de pedagogia de uma universidade pública localizada num município de médio porte do interior paulista, sobre a importância da pesquisa na formação do professor, sendo 13 do sexo feminino e um do sexo masculino, com idade entre 40 a 65 anos e tempo de exercício no magistério no ensino superior entre 03 a 31 anos.

A pesquisa documental compreendeu o estudo do projeto político pedagógico e de 22 planos de ensino de disciplinas que compõem a grade curricular desse curso.

Os depoimentos, registrados em áudio, foram coletados individualmente, nas dependências da unidade universitária onde o curso funciona, em horário previamente disponibilizado pelos participantes e durou, aproximadamente, uma hora. Ressaltamos que todos os professores formadores que atuavam nesse curso de pedagogia foram convidados a participar da pesquisa, mas nem todos, de fato, o fizeram sob alegação de indisponibilidade de tempo, afastamentos e sobrecarga de trabalho. Tais depoimentos foram, posteriormente, transcritos para fins de análise.

O projeto político pedagógico utilizado encontrava-se disponibilizado no formato de domínio público, enquanto que os planos de ensino foram disponibilizados pelos professores participantes. Destacamos que parte desses professores ministrava mais de uma disciplina, por ocasião da coleta de dados.

Desse modo, foram considerados os planos de ensino atinentes às seguintes disciplinas: na área de fundamentos, as disciplinas "Filosofia da Educação", "Psicologia da Educação", "Fundamentos da Educação Inclusiva" e "Fundamentos da Educação Infantil"; no campo das metodologias de ensino, "Conteúdo, Metodologia e Prática do Ensino de Matemática", "Conteúdo, Metodologia e Prática do Ensino de História e Geografia", "Conteúdo, Metodologia e Prática do Ensino de Ciências" e "Conteúdo, Metodologia e Prática da Alfabetização". Também integraram o rol de disciplinas consideradas aquelas relacionadas às atividades de estágio supervisionado: "Prática de Ensino e Estágio Supervisionado para a Educação Infantil"; "Prática de Ensino e Estágio Supervisionado para o Ensino Fundamental"; e "Prática de Ensino e Estágio Supervisionado em Gestão Escolar", bem como a disciplina de "Didática". Mais diretamente relacionadas à pesquisa, propriamente dita, foram consideradas as disciplinas "Pesquisa Pedagógica" e "Trabalho de Conclusão de Curso (TCC)". 
Na área da Educação Infantil foi possível obter os planos de ensino das disciplinas "Arte na Educação Infantil" e "Jogos e Atividades Lúdicas". No campo da gestão escolar foi considerada a disciplina "Administração Educacional: Teoria e Prática" e, na Educação Especial, as disciplinas "Currículo e Necessidades Educacionais Especiais" e "Sistema Braile". No campo dos aprofundamentos, podemos destacar: na Educação Infantil, a disciplina "Psicogênese do Conhecimento"; em Educação Especial, as disciplinas "Sistemas de Comunicação Alternativa"; e, em Gestão Educacional, a disciplina "Gestão do Sistema Educativo e Unidades Escolares".

Evidenciamos que, ainda que não tenham sido analisados os planos de ensino referentes à matriz curricular, em sua íntegra, as disciplinas aqui destacadas encontravam-se distribuídas ao longo dos quatro anos do curso, bem como compreendiam tanto a área básica e comum, que vai do 1 음o 70 semestre, quanto o aprofundamento, de natureza optativa, consolidado no 8 o semestre.

A partir dos dados obtidos com a entrevista e com os documentos utilizados, foi possível configurar a análise sob dois núcleos de significação: "O lugar da pesquisa no discurso do professor formador", subsidiado pelos depoimentos orais; e "O lugar da pesquisa na prática do professor formador", embasado pelo projeto político pedagógico e pelos planos de ensino, aqui compreendidos como representativos da prática norteadora do trabalho docente, explicitados a seguir.

\section{RESULTADOS E DISCUSSÃO}

Conforme mencionado anteriormente, dos dados obtidos depreenderam-se dois núcleos de significação:

\section{O LUGAR DA PESQUISA NO DISCURSO DO PROFESSOR FORMADOR}

Fizemos uso do depoimento oral por se tratar de instrumento privilegiado para a obtenção dos dados e informações com maior abrangência fornecidas pelos próprios participantes, o que permite evidenciar o discurso pedagógico sobre o tema proposto. É sabido que a valorização do discurso docente caracteriza-se como importante possibilidade para a reflexão e ressignificação sobre sua própria prática docente (GIROTO; CASTRO, 2011).

Particularizamos, para essa discussão, os depoimentos dos participantes sobre a importância da pesquisa na formação do professor.

Conforme os dados dispostos no Gráfico 1, dos 14 participantes, cinco afirmaram considerar a pesquisa como aspecto importante na formação do professor, quatro consideraram que não e o restante, cinco, afirmaram depender muito do aluno essa formação. 


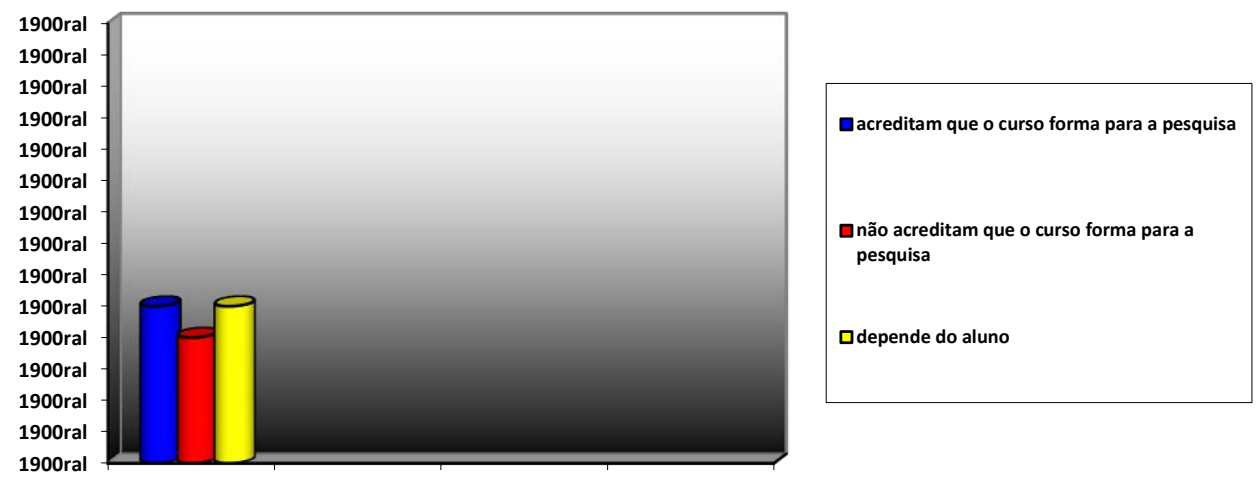

(Fonte: dados da pesquisa)

A partir dos depoimentos obtidos, foi possível identificarmos aspectos destacados e relacionados pelos participantes à compreensão sobre pesquisa e às ações pedagógicas que envolvem o tema na formação de professores.

Os participantes que reconheceram a importância da pesquisa na formação de professores apontaram lacunas nessa formação, como a falta de disciplinas de pesquisa, no caso das grades curriculares antigas, dificuldades para desenvolver a iniciação científica e a participação em grupos de pesquisa.

Explicitaram que suas experiências ocorreram apenas na pós-graduação, quando cursaram o mestrado e doutorado, sem saber ou ter conhecimento do que seria fazer pesquisa e a exigência de rigor desse trabalho, conforme exemplificado nesses depoimentos:

Eu comecei a me formar em pesquisa, fazendo pesquisa no mestrado, mas mesmo quando eu ingressei no mestrado eu não tinha a menor ideia do que era pesquisar; eu passei a ter ideia quando recebi o primeiro parecer do relatório científico que mandei para FAPESP. Era um relatório parcial do mestrado que já estava com um ano e meio de pesquisa e aí o parecerista me acordou e falou assim: "oh, aprenda a fazer pesquisa", a minha bolsa foi cortada naquele momento. Daí comecei a me dar conta do que era fazer pesquisa. ( G.).

\begin{abstract}
Minha experiência com pesquisa só ocorreu pela necessidade de conhecer o processo de alfabetização, mas não foi na área do Magistério Oficial do Estado de São Paulo. Com o impacto da chegada das ideias de Ferreiro na década de 80 houve necessidade de aprofundamento [...] então, mesmo não estando na universidade eu já fazia investigações, na pós-graduação [...] é foi aí que apareceu meus primeiros contatos com a área específica de pesquisa e isso se deu com a disciplina de pós-graduação. (D. B.)
\end{abstract}

A formação continuada stricto sensu (mestrado e doutorado) apareceu como um dos grandes aspectos responsáveis pela formação do pesquisador, momentos em que se impõe a disciplina e os critérios característicos que imprimem o caráter de cientificidade na produção do conhecimento novo.

Tanto os participantes que mencionaram a importância da pesquisa na formação inicial de professores, quanto os que afirmaram que tal importância depende do aluno evidenciaram as contribuições dos grupos de pesquisa para a 
formação do aluno-professor nas trocas de experiências e conhecimentos e também em relação ao desenvolvimento das questões teóricas e metodológicas das pesquisas, conforme aqui exemplificado:

Então eu acho que minha maior formação em pesquisa foi no grupo de pesquisa mesmo, foi quando, como eu falei, com a bolsa do mestrado. Até então não tinha feito pesquisa e com o ingresso e iniciando a minha participação no grupo de Administração, que na época era Organização do Trabalho na Escola [...]. Então eu acho que esse foi o maior aprendizado de pesquisa, de discussão de texto, de metodologia, de teoria, então foi essa formação mesmo e aí eu cursei a disciplina de pesquisa também na pósgraduação, foi quando eu comecei mesmo a entender o processo, e estou tentando até hoje. ( G.).

Conforme afirma Alonso (2011), nos grupos de pesquisa todos os envolvidos partilham as mesmas tarefas, tais como: a discussão dos projetos de pesquisa; a leitura e compreensão dos textos lidos; a apresentação dos diferentes referenciais teóricos; a coleta de dados; e a discussão do material coletado com o intuito de compreender melhor os problemas específicos num contexto composto por diferentes olhares.

Para esses professores, a importância da participação dos alunos nos grupos de pesquisa permite fazer a relação entre os dados coletados empiricamente confrontando-os com os textos teóricos trabalhados nos grupos. A participação nos grupos de pesquisa e a leitura dos textos foi considerada uma boa oportunidade para os alunos participarem de discussões, discutirem as pesquisas que estão sendo realizadas e seus achados.

Teixeira, Passos e Arruda (2015), ao realizarem um estudo sobre a formação de pesquisadores no âmbito de um grupo de pesquisa em Educação em Ciências e Matemática e priorizarem a proposição de focos de aprendizagem, enfatizam que, a participação nesse tipo de atividade, além de contribuir para a formação em pesquisa, pode resultar numa melhor qualidade de dissertações e teses produzidas pelos participantes, bem como para a consolidação de linhas de pesquisa e do próprio grupo como espaço de aprendizagem científica.

Os depoimentos obtidos também apontaram algumas lacunas na formação inicial, como a falta de disciplinas de pesquisa, no caso das grades antigas, dificuldades para o aluno do curso noturno desenvolver iniciação científica e participar de grupos de pesquisa.

[...] o que me chamou a atenção nessa formação em pesquisa foi ter realizado durante o curso de mestrado uma disciplina que eu julgo importante que não tem aqui, que deveria fazer parte do curso de graduação: Filosofia da Ciência. (R. M.).

Entre os procedimentos de pesquisa mais citados por esses participantes, podemos destacar: consultas em diferentes bases de dados, como Scielo e bibliotecas universitárias disponíveis on-line, como a Base de dados da biblioteca da Universidade de São Paulo (USP), Banco de Teses do Centro de Aperfeiçoamento de Pessoal de Ensino Superior -(CAPES), Base de dados da biblioteca da própria universidade. Além da consulta a essas bases de dados online, indicaram a realização de consultas em periódicos científicos específicos, como no caso do ensino de Ciências. 
Na minha disciplina, eu os tenho levado para fazer uma pesquisa na base de dados e ali eles consultam periódicos específicos do ensino de Ciências. Então essa é uma das preocupações, porque mesmo que eu não leve, eu sempre tenho mencionado, ofereço textos, indico sites confiáveis onde eles podem ter acesso a isso, porque é uma coisa que eu sempre falo, eles têm que estar em contato com o que é produzido na área, nas discussões que estão ocorrendo na área. [...] Eles acessam os sites, a gente entra com as palavras-chave: ensino de ciências; formação de professores; educação ambiental, então eles entram com as palavras-chave e escolhem um texto para daí fazerem uma resenha desse texto. Então, para eles terem um contato, conhecer, saber quais são, onde esses trabalhos estão sendo publicados, essa é a preocupação. Outro momento que eu também acho que no fundo eles estão tendo contato com a pesquisa são algumas atividades extras, é dentro da programação; mas elas são feitas fora da universidade, eu os levo para conhecerem os trabalhos feitos em outros campi [...] acho que isso ajuda na construção do conhecimento deles, além do que a gente trabalha em sala de aula. (B. B.).

No caso específico das disciplinas que envolvem práticas de ensino e estágio supervisionado, os participantes responsáveis por essas disciplinas mencionaram incentivar os alunos para o uso de instrumentos para os registros de dados, a exemplo do diário de campo, utilizado para o registro das impressões acerca das atividades realizadas para depois, na elaboração do relatório, eles terem condições de retomar as anotações como elementos que poderão gerar dados relevantes, trazer os pressupostos teóricos apreendidos durante o curso e tentar dialogar com aquilo que eles conseguiram fazer emergir do cotidiano das salas de aula observadas.

Mencionaram, ainda, o uso de roteiros de observação e de entrevistas, principalmente aqueles que trabalhavam com as disciplinas de Prática de Ensino e Estágio Supervisionado, docentes das áreas de Educação Infantil, Gestão Educacional e Pesquisa. Disciplinas que focam a prática cotidiana e permitem que os alunos assumam suas experiências como fonte de conhecimento.

[...] eu trabalho os clássicos da administração, mas desde, por exemplo, o segundo texto que a gente trabalha com a função do diretor de escola, eles vão buscar entrevistas com pais, alunos, funcionários, professores e a equipe de gestão, sobre a função do diretor, o que eles acham que é, como acham que é, e aí a gente faz um confronto, um diálogo entre as respostas que eles trouxeram com os textos teóricos que a gente está trabalhando. (G.)

Em suas atividades, os participantes que consideraram importante a pesquisa na formação inicial de professores e os que afirmaram depender do aluno, se aproximaram mais do uso dos instrumentos para coleta de dados utilizados como recurso didático do que da pesquisa, em si. Em alguns casos esses instrumentos foram utilizados para subsidiar questões práticas e dificilmente se aproximaram de um conceito de pesquisa propriamente dito.

Cabe esclarecer, entretanto, que o termo pesquisa foi utilizado por esses participantes para designar uma variedade de atividades. A maioria dos professores afirmou trabalhar com procedimentos de investigação bem diferenciados. Em muitos casos, porém, sem a preocupação de articular tais procedimentos com os referenciais teóricos das suas disciplinas e com atividades mais sistemáticas e regulares de investigação, o que sugeriu uma compreensão reducionista acerca do conceito de pesquisa. 
As pesquisas de natureza bibliográfica e documental foram citadas como as mais utilizadas nas aulas por esses participantes. Observamos em seus depoimentos o incentivo a esses tipos de pesquisa. Mencionaram que o contato dos alunos com a pesquisa é mais pela leitura de autores que realizaram pesquisas pertinentes ao conteúdo trabalhado em sala de aula.

No entanto, é preciso tomar cuidado com a concepção de pesquisa e o modo como é apresentada aos alunos.

[...] eu tenho motivado o pessoal para pesquisa, até mesmo com relação aos temas que a gente discute em sala de aula, e tentar fazer com que eles busquem os temas ou professores ou grupos que já estejam atuando bastante na pesquisa, nos estudos [...] A gente fala de pesquisa e tem ocorrido bastante: pesquisa pra vocês o que vem em mente? aí eles já falam "Internet", "pesquisa é ir lá num site de busca", põem lá o termo que eles querem e é uma pesquisa [...] eu falo: isso não é pesquisa, também faz parte de uma pesquisa, [...] pesquisa não é somente você ir num site de busca, pesquisa é você se envolver com algum tema e fazer leitura, buscar livros, revistas, períodos, sites também, mas fazer a leitura disso que é o que falta [...] Acho que a contribuição vai nesse sentindo, tentar envolvê-los nesse campo de pesquisa independente da temática que cada um vai aprofundar/escolher. (C.).

Ainda que no depoimento anterior o participante tenha manifestado a necessidade de problematização sobre a concepção de pesquisa, sua compreensão sobre essa temática e suas orientações aos alunos não evidenciaram a preocupação com os aspectos que caracterizam a cientificidade dos procedimentos mencionados.

Quanto aos estudos de caso, foram mais utilizados pelos formadores que atuavam com as disciplinas da área de Educação Especial, conforme o depoimento abaixo:

Na minha disciplina, por exemplo, Currículo e Necessidades Educacionais Especiais, além da parte da formação acadêmica que a gente desenvolve através dos textos a formação teórica vamos dizer assim da metade para o final da disciplina, os alunos precisam desenvolver um estudo de caso numa instituição que tenha um aluno com deficiência incluído numa classe. Então esses alunos fazem uma pesquisa, verdadeiramente pesquisa, porque eles realizam, desenvolvem instrumentos de coleta de dados, desenvolvem uma pesquisa documental, junto ao projeto político da escola, ao planejamento do professor, semanário, a produção do aluno em classe, então eles fazem uma análise do processo de inclusão desse aluno com deficiência nessa classe, nessa escola. Posteriormente eles apresentam o trabalho para a turma toda em forma de seminário e demonstram o resultado da pesquisa desenvolvida nessa escola, com esse professor, com esse aluno. (F. I.)

Além da experiência na sala de aula, os trabalhos de extensão universitária também foram mencionados como relevantes.

[...] a gente tem incentivado os alunos a participarem de projetos de intervenção como o Núcleo de Ensino, projetos de extensão universitária, onde há sempre a cobrança de produção de algum trabalho cientifico, apresentação nos congressos, até para publicação, e o PIBID que eu acho que é uma forma de perspectiva de formação do professor, atuando, intervindo nas escolas. É uma dimensão de incentivo a docência, mas que eu entendo que deva existir uma preocupação de pesquisar sobre a prática docente através do PIBID. (J. C.). 
A participação dos alunos em eventos científicos também foi considerada como relevante na formação para a pesquisa, como meio dos estudantes terem acesso às pesquisas que estão sendo produzidas na área e como iniciação dos alunos na apresentação de comunicações científicas.

De um modo geral, esses participantes destacaram o uso de técnicas como as observações, entrevistas, o uso de documentos, filmagens, portfólios, diários de bordo e o uso de protocolos. No entanto, entre os depoimentos e os planos de ensino reside uma incongruência. Embora muitos professores afirmaram fazer uso da pesquisa em suas disciplinas, suas atividades se aproximaram mais do uso de instrumentos para a simples coleta de dados do que propriamente para a pesquisa e, ainda que essas informações figurassem na fala dos professores, o mesmo não aconteceu em seus planos de ensino. Nem todos os planos dos professores que afirmaram fazer uso desses recursos apresentaram essa atividade como proposta. Ademais, a compreensão demonstrada por alguns sobre o uso desses instrumentos nos pareceu bastante restrita. Ou seja, a preocupação com o teor científico da pesquisa não foi evidenciado nas práticas mencionadas.

Contudo, parte dos professores propuseram o trabalho com a pesquisa acadêmica, destacando-se aqueles também credenciados a programas de PósGraduação, que orientavam pesquisas de mestrado e doutorado e envolviam alunos de graduação em suas pesquisas.

\begin{abstract}
De um modo geral, somente as disciplinas "Metodologia da Pesquisa Científica", "Pesquisa Pedagógica" e o "Trabalho de Conclusão de Curso" pareceram ser as responsáveis pela iniciação sistemática do aluno na pesquisa. Não! Não acredito! Tenho a minha própria prática como professora das disciplinas que eu ministro, eu não formo o meu aluno para a pesquisa dentro da disciplina da forma como eu gostaria, eu vejo que eu fico presa muito mais a questões de conteúdo, porque eu acho que eu poderia até repensar depois dessa sua entrevista, como conseguir isso e, com certeza, eu acho que a própria aprendizagem do conteúdo da disciplina seria melhor. Então, em relação ao curso de uma forma geral, entrevistando os próprios alunos e mesmo na minha atuação dentro do conselho de curso eu acho que não acaba, eu acho que fica muito nas disciplinas específicas, na Metodologia Científica, TCC, Pesquisa Pedagógica e naqueles alunos que se inserem em grupos de pesquisa. Mas tem aluno do 4 을 ano que eu peguei para orientar no TCC que eu percebo que não tem a mínima noção de pesquisa e, geralmente, são aqueles alunos que, por mais contraditório que seja, que são professores e que não puderam se envolver em grupos de pesquisa, em bolsas PIBIC e que então são professores e não são pesquisadores e o ideal é que se forme o professor pesquisador, o trabalho docente seria outro, então não acredito que forme, falando de mim e de tudo aquilo que eu percebi dentro do próprio curso. Nós precisaríamos modificar as nossas estratégias dentro das nossas disciplinas. Eu acho que muitos professores deixam isso só para as atividades específicas, mas não veem isso como um eixo que deveria perpassar todas as disciplinas. (A. S.).
\end{abstract}

Quanto aos participantes que afirmaram não reconhecer a importância da pesquisa na formação de professores, cabe destacar que afirmaram não trabalhar com a pesquisa ou com atividades de investigação, tampouco demonstraram a preocupação que o aluno aprenda a linguagem da pesquisa científica, sua natureza e seus fins.

A análise desse material nos permitiu considerar que é o envolvimento com a pesquisa que marca os depoimentos dos professores e não o aprendizado 
adquirido nas disciplinas de Licenciatura. Muitos docentes pareceram desconsiderar que as disciplinas ministradas na graduação tenham contribuído para o seu aprendizado no campo da pesquisa. Destacaram outras experiências que foram mais significativas, como o auxílio de bolsas ou o envolvimento nos projetos de pesquisa de seus professores formadores.

Aprender a pesquisar deve fazer parte do cotidiano escolar, especificamente da sala de aula. Segundo Veiga (2004, p.21) o pesquisador precisa ser formado e essa formação "[...] só pode vir no bojo de sua prática dentro de um contexto social". Sendo assim, o professor/aluno precisa aprender a pesquisar por meio das situações vivenciadas dentro da sala de aula, a pesquisar pesquisando assuntos de seu convívio e interesse, pois somente assim alunos e professores podem assumir o papel de "[...] protagonistas e agentes sociais".

Não houve consenso sobre a formação que o curso de pedagogia oferece em relação à pesquisa, se habilita o futuro professor para a pesquisa.

Ensinar a pesquisar significa estimular a criatividade, o espírito investigativo, a curiosidade. A pesquisa é atividade inerente ao ser humano, um modo de apreender o mundo. Ensinar a pesquisar é orientar para tomar a pesquisa como instrumento de ensino, de aprendizagem e de avaliação. É o ponto de partida e de chegada da apreensão da realidade (VEIGA, 2004, p. 16).

A formação do espírito investigativo no aluno é um processo lento que não ocorre de um dia para outro. No entanto, embora o processo seja lento e se dê aos poucos, precisa ser alimentado constantemente pela figura do professor. Entendemos que esse processo deve ser iniciado durante a sua vivência na universidade, ao longo de sua formação inicial e alimentado pela iniciação científica, momento no qual se espera que o aluno tenha um contato maior com os processos de pesquisa, uma vez que ele poderá participar, como bolsista ou não, de grupos de estudos, grupos de pesquisa, de eventos científicos apresentando trabalhos produzidos por ele sob orientação de um docente responsável e trocando experiências com outros pesquisadores mais experientes.

Reconhecemos que no campo da formação dos professores persistem problemas há muito tempo sentidos pela comunidade educacional. Os cursos de licenciatura em pedagogia e os profissionais que neles são formados vivem hoje uma crise de identidade, marcada pela ambiguidade da atual legislação sobre as funções que deve desempenhar. Também é fato a ineficácia na atuação profissional do professor, o que provoca o debate sobre qual é o papel do pedagogo nos dias de hoje, afirmando a Pedagogia como um campo de conhecimento e o pedagogo como ator principal de sua produção.

\section{O LUGAR DA PESQUISA NA PRÁTICA DOS PROFESSORES}

O estudo do projeto político pedagógico revelou que esse curso de pedagogia surgiu em 1959, quando a unidade universitária à qual pertence ainda funcionava na condição de faculdade, com o objetivo de formar profissionais na área da administração educacional. Em 1975, com a criação da instituição de ensino superior (IES) que assumiu o status de universidade multicampi, tal unidade universitária passou a integrar essa IES, de maneira que esse curso passou a formar o professor para atuar tanto no ensino primário, quanto no curso de magistério. 
Em 2006, com as Diretrizes Curriculares Nacionais para o Curso de Pedagogia (BRASIL, 2006), esse curso teve suas habilitações extintas, o que deflagrou uma reestruturação curricular. Atualmente é constituído por 3360 horas, devendo ser cursadas 105 horas de disciplinas optativas e 300 horas em um dos três aprofundamentos, totalizando 3360 horas. 0 curso é previsto para 4 anos e o estudante de pedagogia poderá concluir os créditos em até 07 anos. Oferece 40 vagas para o período matutino e 80 para o noturno. É constituído por: um núcleo de estudos básicos, "[...] destinado aos fundamentos da educação, para as teorias, conteúdos, metodologias e práticas do ensino e as teorias e práticas de gestão"; três núcleos de aprofundamento, de natureza optativa, "[...] dedicados à Educação Infantil, à Educação Especial e à Gestão Educacional". Em relação a esses três núcleos, "[...] o graduando deverá optar por um destes núcleos, que serão oferecidos para duas turmas: uma no matutino e outra no noturno, ministrados no último semestre do 4ㅇ ano"; e um núcleo de estudos integradores, "[...] constituído por projeto, programa de estudos ou de atividades a ser elaborado pelos professores e estudantes de cada semestre, em cada uma das turmas, exceto no último semestre do curso". Nesse núcleo, "[...] as atividades programadas objetivarão articular a integração das disciplinas do semestre em torno de um eixo temático comum" (UNESP, 2006).

Cabe ressaltar que, "[...] os estudos integradores têm caráter teórico-prático, portanto, distintos de aulas e deverão corresponder a 15 horas da carga horária de cada disciplina de 75 horas" (UNESP, 2006), tal como explicitam os planos de ensino.

Em relação aos Estágios Supervisionados, as áreas contempladas são: "Estágio Supervisionado de Prática de Ensino na Educação Infantil"; "Estágio Supervisionado de Prática de Ensino nos Anos Iniciais do Ensino Fundamental"; e "Estágio Supervisionado de Gestão Educacional". Esses estágios têm início no primeiro semestre do 3 o ano e podem ser concluídos até o final do curso. Cada área conta com 135 horas de atividades, distribuídas da seguinte forma: 25 horas teóricas; e 110 horas práticas. Nas horas práticas são contempladas 20 horas de estágio com alunos público-alvo da educação especial, inseridas no ensino regular e, no caso do Estágio em Gestão Educacional, 20 horas para desenvolvimento de ações para a educação inclusiva.

Quanto à pesquisa, a unidade universitária propicia, por meio de seu escritório de pesquisa, da Seção Técnica de Apoio ao Ensino, Pesquisa e Extensão (STAEPE) e de laboratórios com infraestrutura apropriada (informática, didática, educação especial, dentre outros), respaldo ao desenvolvimento de atividades de iniciação científica. Muitos estudantes têm, ainda, a oportunidade de serem contemplados com bolsas vinculadas à própria universidade e às agências de fomento, tais como: Fundação de Amparo à Pesquisa do Estado de São Paulo (FAPESP); Conselho Nacional de Desenvolvimento Científico e Tecnológico (CNPq); e Coordenação de Aperfeiçoamento de Pessoal de Nível Superior (CAPES), bem como de participarem de grupos de estudos e/ou de pesquisas credenciados junto ao CNPq.

No que diz respeito à extensão, há vários projetos vinculados a esse curso de pedagogia que se constituem em estruturas facilitadoras da articulação entre ensino, pesquisa e extensão, dentre os quais se destaca o Programa Institucional de Bolsas de Iniciação à Docência (PIBID). 
Quanto ao perfil de seus alunos, este é constituído por estudantes de todas as regiões do Brasil. Esses estudantes, em sua maioria, são das classes populares, oriundos de escolas públicas e, na maioria, do sexo feminino. Muitos desses estudantes já desempenham atividades profissionais, inclusive na área da educação, por terem cursado Magistério ou o Centro Específico de Formação e Aperfeiçoamento do Magistério (CEFAM).

Os planos de ensino utilizados para esta análise foram selecionados tendo em conta os professores que se disponibilizaram a participar da pesquisa, mas também buscando priorizar disciplinas que estivessem distribuídas nos quatro anos do curso. Foram considerados 22 planos de ensino, sendo que parte dos 14 professores ministravam mais de uma disciplina no curso.

Com base nos planos de ensino analisados, foi possível identificar que a preocupação em formar o aluno-professor para a pesquisa é mais forte nas disciplinas voltadas para essa área específica, como a "Pesquisa Pedagógica" e "Trabalho de Conclusão de Curso". Essa preocupação aparece tanto na ementa, quanto nos objetivos e metodologia de ensino das disciplinas.

Dos 22 planos de ensino examinados, apenas 07 disciplinas apresentaram informações sobre o envolvimento dos alunos em atividades de pesquisas, ou seja, apenas um terço delas. São as seguintes: "Pesquisa Pedagógica"; "Trabalho de Conclusão de Curso"; "Administração Educacional: teoria e prática"; "Conteúdo, Metodologia e Prática do Ensino de Ciências"; "Psicologia da Educação e Gênese do Conhecimento"; "Conteúdo, Metodologia e Prática do Ensino de Alfabetização", conforme as indicações do Gráfico 2:

Gráfico 2 - Desenvolvimento de pesquisas na graduação

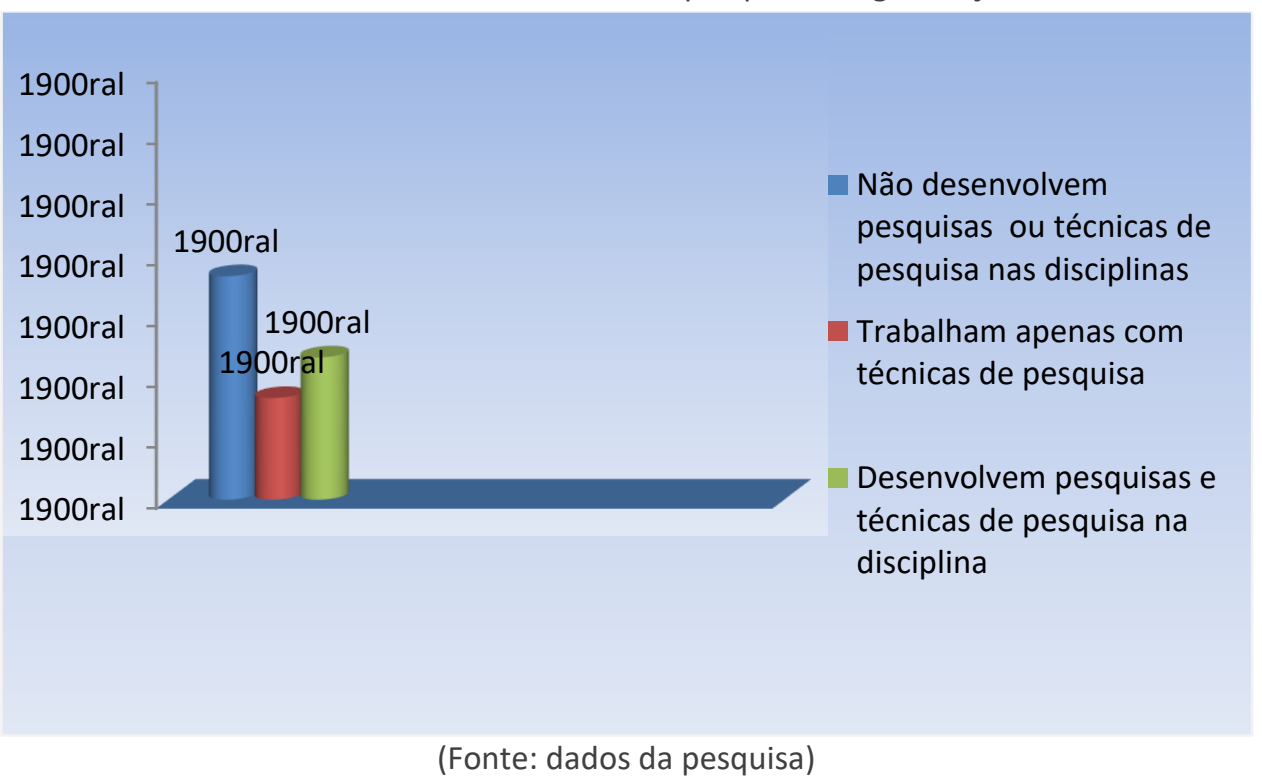

As pesquisas mais recorrentes nas práticas dos docentes são a pesquisa bibliográfica indicada pelas disciplinas "Psicologia da Educação", "Administração Educacional: teoria e prática", "Conteúdo, Metodologia e Prática do Ensino de Ciências", "Psicogênese do Conhecimento", "Pesquisa Pedagógica", "Trabalho de Conclusão de Curso" e o trabalho de campo, frequentemente promovido pelas 
As disciplinas de "Pesquisa Pedagógica" e "Trabalho de Conclusão de Curso", por se tratarem de disciplinas que orientam a construção e acompanhamento de projetos de pesquisa abordam diferentes tipos de pesquisa como: bibliográfica; etnográfica; estudos de caso; pesquisa-ação; pesquisa colaborativa; pesquisa participante; pesquisa histórica; e estado da arte.

Quanto às técnicas utilizadas, a observação foi a mais frequentemente indicada nos planos de ensino das disciplinas: "Filosofia da Educação II"; "Prática de Ensino e Estágio Supervisionado para a Educação Infantil e Ensino Fundamental"; "Prática de Ensino e Estágio Supervisionado para a Gestão Escolar"; "Sistema Braile"; "Comunicação e Sinalização Diferenciadas na Educação Especial"; e "TCC". Em seguida, os documentários foram mais frequentemente indicados, conforme apresentados nos planos de ensino das disciplinas de "Didática", "Conteúdo, Metodologia e Prática de História e Geografia" e "TCC". A entrevista foi indicada apenas pelas disciplinas de "Gestão Educacional: teoria e prática" e "TCC". Os relatos de experiência foram mais considerados nos planos de ensino das disciplinas "Conteúdo, Metodologia e Prática de História e Geografia" e "TCC"; enquanto que o uso dos Projetos Educacionais constou nos planos das disciplinas "Conteúdo, Metodologia e Prática do Ensino de Ciências" e os Projetos de Estágio figurou no plano de ensino da disciplina "Prática de Ensino e Estágio Supervisionado na Educação Infantil e Ensino Fundamental". A disciplina de Pesquisa Pedagógica prevê o uso de diferentes técnicas de coleta de dados, mas não explicita as mais usadas.

Os dados coletados, mediante análise dos planos de ensino, demonstraram que uma pequena parcela de professores trabalha pesquisas com seus alunos em sala de aula, a maioria deles faz uso de procedimentos de pesquisa, muitas vezes, como recurso didático e nem sempre acompanhados do rigor científico necessário ao desenvolvimento da pesquisa. Ademais, nem todos os planos de ensino foram atualizados pelos docentes.

A bibliografia presente nos planos de ensino permitiu considerar que as atividades de pesquisa devem se constituir como uma rotina no curso de pedagogia. A incorporação da prática da pesquisa ao currículo da pedagogia poderia trazer contribuições para uma mudança de cultura do próprio curso, no que diz respeito à articulação entre teoria e prática. Além disso, requer um amadurecimento de todos os professores envolvidos de certa forma com os trabalhos de pesquisa, seja no desenvolvimento de pesquisas bibliográficas, pesquisas de campo, na construção, orientação e avaliação dos trabalhos científicos, ou simplesmente no desenvolvimento de procedimentos de geração de dados que, orientados com rigor científico, podem contribuir para fomentar o interesse pela pesquisa no processo de formação inicial e continuada de professores.

Com base nos planos de ensino analisados, foi possível identificar que a preocupação em formar o aluno-professor para a pesquisa é mais forte nas disciplinas voltadas para essa área específica: "Pesquisa Pedagógica"; e "Trabalho de Conclusão de Curso". Essa preocupação aparece tanto na ementa, quanto nos objetivos e metodologias de ensino dessas disciplinas.

Dos 22 planos de ensino examinados, apenas 07 disciplinas trazem informações sobre o envolvimento dos alunos em atividades de pesquisas, ou seja, apenas um terço delas. São as seguintes: "Pesquisa Pedagógica"; "Trabalho 
de Conclusão de Curso"; "Administração Educacional: teoria e prática"; "Conteúdo, Metodologia e Prática do Ensino de Ciências"; "Psicologia da Educação e Gênese do Conhecimento"; e "Conteúdo, Metodologia e Prática do Ensino de Alfabetização".

A "Pesquisa Pedagógica" propõe em sua ementa situar a pesquisa educacional no âmbito da investigação científica considerando a discussão sobre a pesquisa quantitativa e qualitativa. Além disso, visa discutir os principais tipos de pesquisa utilizados na área de educação e suas estratégias metodológicas apontando os limites e possibilidades de cada uma delas, enfocando também as contribuições da pesquisa pedagógica para a formação de professores. Tem por objetivos identificar as várias abordagens metodológicas e técnicas de pesquisa em educação com maior ênfase para aquelas utilizadas nas pesquisas pedagógicas; esboçar um projeto de pesquisa visando à iniciação dos alunos na área e fazer da pesquisa pedagógica um dos instrumentos de formação acadêmica e de qualificação da ação docente. Apresenta como metodologia de ensino o desenvolvimento de aulas expositivas, discussão de textos, análise de relatos de pesquisas, apresentação de seminários e debates, atividades de pesquisa, apresentação de comunicações orais e atividades para realização do projeto de pesquisa (8 horas/aula).

Na disciplina de "Trabalho de Conclusão de Curso" são discutidas as seguintes questões: a metodologia do trabalho científico: discussões preliminares; a pesquisa quantitativa e a pesquisa qualitativa; diferentes tipos de pesquisa (pesquisa bibliográfica, exploratória, descritiva e experimental); a pesquisa em educação e as abordagens qualitativas (pesquisa etnográfica, estudo de caso, pesquisa participante, pesquisa-ação e pesquisa colaborativa). Também são discutidas a pesquisa histórica e o estado da arte. Além disso, as preocupações da disciplina também se voltam para os procedimentos de geração de dados: observação; entrevistas; análise de documentos; formulários e questionários; análise de dados; comitê de ética; seminários de trabalho de conclusão de curso; o trabalho monográfico; e orientação e supervisão do trabalho referente às questões estruturais e metodológicas dos projetos de pesquisa. Apresenta como objetivos: identificar os vários tipos, abordagens e técnicas de pesquisa; compreender o papel do comitê de ética em pesquisa; bem como conhecer os documentos que devem ser encaminhados para analise; participar do Seminário de trabalho de conclusão de curso; orientar e supervisionar os projetos de pesquisa, assim como a apresentação oral das pesquisas desenvolvidas mediante defesa. Como metodologia de ensino são utilizadas aulas expositivas, discussão de textos, debates, atividades de pesquisa, apresentação da pesquisa num seminário, orientação e supervisão das pesquisas.

Além dessas duas, podemos destacar a disciplina de "Administração Educacional: teoria e prática", que traz como metodologia, aulas expositivas, leitura e discussão de textos, pesquisa bibliográfica, apresentação de painéis, entrevistas nas escolas e contrapontos com os conteúdos discutidos em sala de aula, trabalhos em grupo e estudos de caso, bem como a disciplina de "Conteúdo, Metodologia e Prática do Ensino de Ciências", que tem sua metodologia de trabalho assegurada pelas leituras e discussões orientadas, aulas expositivas, produção de textos e resenhas, pesquisa na biblioteca sobre artigos relacionados ao ensino de ciências, oficinas pedagógicas, desenvolvimento de projetos educacionais, atividades extraclasse e excursões didáticas. 
As disciplinas de "Psicologia da Educação" e "Psicogênese do Conhecimento" trazem como metodologia de ensino aula expositivo-dialogada, para fornecimento das bases conceituais necessárias, análise e discussão de textos, vídeo, fórum, vivências e dinâmicas, pesquisa bibliográfica e atividades de campo.

Destacamos também os objetivos da disciplina de "Conteúdo, Metodologia e Prática do Ensino de Alfabetização", que visa elaborar os princípios norteadores para realização de pesquisas na área da alfabetização e da leitura no início do processo de escolarização. Utiliza técnicas como: exposição de temas teóricos pelo docente; leitura prévia dos artigos selecionados e discussão em sala de aula; discussão de dados coletados pelos alunos em escolas; discussão de sequências didáticas realizadas no cotidiano das escolas de educação infantil e ensino fundamental; apresentação em vídeo de situações de pesquisa; mas não deixa claro que situações de pesquisa são essas.

As disciplinas "Filosofia da Educação II", "Conteúdo, Metodologia e Prática do Ensino de História e Geografia", "Didática" e "Prática de Ensino e Estágio Supervisionado em Gestão Escolar" não preveem como parte de sua atividade o envolvimento dos alunos em atividades de pesquisa propriamente dita, mas trazem em seus planos de ensino a proposta de algumas técnicas de pesquisa, tais como: desenvolvimento de observações; entrevistas; protocolos; relatos de experiências; uso de documentários; análise de documentos; e desenvolvimento de projetos de estágio. Todavia, ressaltamos que essas atividades nem sempre são orientadas pelo rigor científico.

A ementa da disciplina de "Psicologia da Educação" traz a preocupação de verificar a contribuição da pesquisa psicológica para a ação pedagógica e para a constituição de teorias e práticas a respeito da relação ensino-aprendizagem.

A disciplina de "Filosofia da Educação II" propõe a observação como uma de suas metodologias de ensino.

"Conteúdo, Metodologia e Prática do Ensino de História e Geografia" propõe como metodologia de ensino problematizações sobre a situação atual do ensino de história e de geografia na educação infantil e nas séries iniciais do ensino fundamental, debates com professores da rede oficial de ensino para relatos de experiências, seminários temáticos, exibição e debate sobre filmes e/ou documentários, atividades extraclasse (comportando $15 \mathrm{~h} / \mathrm{a}$ ) que deverão resultar na elaboração de material didático para o ensino de história e de geografia na educação infantil e nas séries iniciais do ensino fundamental.

Em "Didática" a proposta é a de trabalhar com documentários e apresentação, na sala de aula, das pesquisas realizadas. No entanto, não são explicitadas, no plano de ensino, que pesquisas são essas.

Na disciplina de "Estágio Supervisionado em Gestão Escolar" o procedimento básico da disciplina compreende a elaboração de um projeto de estágio que contemple um problema relacionado à gestão educacional e que seja de interesse do aluno.

As pesquisas mais recorrentes nas práticas dos docentes são a pesquisa bibliográfica, indicada pelas disciplinas "Psicologia da Educação", "Administração Educacional: teoria e prática", "Conteúdo, Metodologia e Prática do Ensino de Ciências", "Psicogênese do Conhecimento", "Pesquisa Pedagógica" e "Trabalho de Conclusão de Curso", e o trabalho de campo, mais frequentemente indicado 
nos planos de ensino das disciplinas "Psicologia da Educação" e "Psicogênese do Conhecimento".

As disciplinas de "Pesquisa Pedagógica" e "Trabalho de Conclusão de Curso", por caracterizarem disciplinas que orientam a construção e acompanhamento de projetos de pesquisa, abordam diferentes tipos de pesquisa como: bibliográfica; etnográfica; estudos de caso; pesquisa-ação; pesquisa colaborativa; pesquisa participante; pesquisa histórica; e estado da arte.

Quanto às técnicas utilizadas, a observação é a mais frequentemente utilizada pelas disciplinas: "Filosofia da Educação II"; "Prática de Ensino e Estágio Supervisionado para a Educação Infantil e Ensino Fundamental"; "Prática de Ensino e Estágio Supervisionado para a Gestão Escolar"; "Sistema Braile"; "Comunicação e Sinalização Diferenciadas na Educação Especial"; "Trabalho de Conclusão de Curso". Em seguida vêm os documentários utilizados pelas disciplinas "Didática", "Conteúdo, Metodologia e Prática de História e Geografia" e "Trabalho de Conclusão de Curso". A entrevista é uma técnica usada pelas disciplinas "Gestão Educacional: teoria e prática" e "Trabalho de Conclusão de Curso". Os relatos de experiência são mais utilizados pelas disciplinas "Conteúdo, Metodologia e Prática de História e Geografia" e "Trabalho de Conclusão de Curso". Os projetos educacionais são usados pela disciplina de "Conteúdo, Metodologia e Prática do Ensino de Ciências" e os projetos de estágio pela disciplina "Prática de Ensino e Estágio Supervisionado na Educação Infantil e Ensino Fundamental". A disciplina de "Pesquisa Pedagógica" prevê o uso de diferentes técnicas de coleta de dados, mas não explicita as mais usadas.

As demais disciplinas não explicitam, em seus planos de ensino, o desenvolvimento de pesquisas ou técnicas de pesquisa que envolvam os alunos, são elas: "Fundamentos da Educação Infantil"; "Fundamentos da Educação Inclusiva"; "Conteúdo, Metodologia e Prática do Ensino da Matemática"; "Prática de ensino e Estágio Supervisionado para a Educação infantil e as séries iniciais do Ensino Fundamental"; "Jogos e atividades lúdicas"; "Arte e Educação Infantil"; "Sistema Braile"; "Currículo e as Necessidades Educacionais Especiais"; "Gestão dos Sistemas Educativos e Unidades Escolares"; "Comunicação e Sinalização Diferenciadas na Educação Especial". Apresentam como propostas didáticas aulas expositivas, precedidas da indicação de textos para a leitura, seminários desenvolvidos pelos alunos, leituras e discussão, em sala de aula, de artigos, de livros, revistas, jornais, atividades práticas e extraclasse, vídeos, documentários, fórum, vivências e dinâmicas.

Os dados coletados mediante análise dos planos de ensino demonstram que uma porcentagem muito pequena de professores trabalha pesquisas com seus alunos em sala de aula, a maioria deles faz uso de procedimentos de pesquisa, muitas vezes como recurso didático e nem sempre acompanhados do rigor científico necessário ao desenvolvimento da pesquisa. Ademais, nem todos os planos de ensino foram atualizados pelos docentes.

A bibliografia examinada sugere que as atividades de pesquisa devem se constituir como uma rotina no curso de pedagogia. A incorporação da prática da pesquisa ao currículo da pedagogia poderia assim trazer contribuições para uma mudança de cultura do próprio curso no que diz respeito à articulação entre teoria e prática. Além disso, requer um amadurecimento de todos os professores envolvidos em alguma medida com os trabalhos de pesquisa, seja no 
desenvolvimento de pesquisas bibliográficas, pesquisas de campo, na construção, orientação e avaliação dos trabalhos científicos, ou simplesmente no desenvolvimento de procedimentos de geração de dados que, orientados com rigor científico, podem contribuir para fomentar o interesse pela pesquisa no processo de formação inicial e continuada de professores.

\section{CONCLUSÕES}

Embora o Projeto Pedagógico do curso de Pedagogia considerado neste estudo proponha a articulação entre ensino, pesquisa e extensão, o acesso do aluno de graduação às oportunidades de participação em projetos desenvolvidos na universidade na qual tal curso é oferecido não pareceu ser necessariamente assegurado.

Não observamos mecanismos que garantam a participação de todos os alunos nesses projetos, principalmente dos alunos trabalhadores, que constituem clientela numerosa do curso de Pedagogia dessa instituição. O público-alvo desse curso é constituído, em sua maioria, por alunos trabalhadores e as oportunidades de acesso, por parte dos alunos, às atividades de iniciação científica são restritas, assim como é restrita a participação desses alunos em grupos de pesquisa.

Pela investigação percebemos que, na maioria das vezes, a formação para a pesquisa tem sido encaminhada por iniciativas de alguns docentes da universidade, que incentivam ou convidam os alunos a participarem de seus grupos de pesquisa. $\mathrm{Na}$ medida em que os alunos aproveitam essas possibilidades, passam a se familiarizar com os diferentes aspectos que envolvem a pesquisa.

Ademais, os cursos de pedagogia apresentam um currículo marcado pela separação entre as disciplinas teóricas, de conteúdos específicos, ou chamadas disciplinas de fundamentos, e aquelas voltadas para a preparação prática, concentradas em estágios e denominadas como disciplinas de "Conteúdos, Metodologias e Práticas de Ensino". Temos clareza que a forma pelo qual o currículo do curso de Pedagogia encontra-se organizado acaba deixando a desejar em relação à pesquisa.

Assim como entendemos que apenas a inserção da pesquisa nos currículos dos cursos de Pedagogia, por si só, não garante a formação do pesquisador, embora entendamos esse fomento do espírito investigativo como necessário à formação do professor, independentemente se ele terá tendências para se dedicar a pesquisa ou não. É nesse sentido que acreditamos ser necessário oferecer ao aluno-professor as bases da cientificidade e compreender como o princípio da pesquisa tem se materializado na sua formação, quais os problemas enfrentados e as suas relações com os modelos formativos elaborados e implantados pelos cursos.

Acreditamos que ninguém pode se tornar um professor e também pesquisador sem compreender a dimensão e os limites da pesquisa em educação. Pensamos ser possível a formação de um professor que incorpora em seu trabalho docente atividades investigativas e, por esse motivo, nos preocupamos com a estruturação do currículo que forma esse professor. É fundamental que os alunos durante a sua formação tenham a possibilidade de discutir a pesquisa, sua natureza e seus fins. 
O estudo empreendido suscitou algumas reflexões, a saber: como fazer a pesquisa de fato corresponder às ansiedades dos professores? Como corresponder às expectativas de quem vem fazer o curso de pedagogia? Será que a pesquisa contribuirá, de fato, para a formação do educador e favorecerá a sua prática pedagógica?

São questionamentos que poderão ser abordados em futuras pesquisas, com vistas a aprofundar o estudo da temática ora evidenciada. 


\title{
Between discourse and practice: the place of research in teacher education
}

\begin{abstract}
Among the various aspects that permeate the discussion about teacher training, we highlighted the role of research as a relevant component in the educational field and necessary in the training process of these professionals. The purpose of this study, using a documentary and field nature, was to investigate the comprehension of trainers in college education about the importance of research in initial teacher education. In order to collect data, we used oral testimony from 14 teachers of the Pedagogy course mentioned, as well as documental analysis, which included the pedagogical political project of this course and 22 teaching plans that are available in public domain format. It was possible to show inconsistencies in the research policies of this Institution, particularly regarding the reductionist understanding about research and the practices proposed for the teaching performance with this subject in disciplines taught, restricted to the use of some techniques of data collection.
\end{abstract}

KEYWORDS: Education. Teacher training. Research. 


\section{REFERÊNCIAS}

ABREU, R. M. A.; ALMEIDA, D. M. Refletindo sobre a pesquisa e sua importância na formação e na prática do professor do ensino fundamental. Revista Entreideias: Educação, Cultura e Sociedade, n. 14, p. 73-85, 2008.

ALONSO, M. A formação de pesquisadores-Educadores: Desafio para os programas de pós-graduação. In: FAZENDA, I. LINHARES, C. (Org.). Os lugares dos sujeitos na pesquisa educacional. Campo Grande: Ed. UFMS, 2001, p. 426-437.

BRASIL. Lei no 9394, de 20 de dezembro de 1996, estabelece as diretrizes e bases da educação nacional. Disponível em:

http://www.planalto.gov.br/ccivil_03/leis/L9394.htm Acesso em: 19 jul. 2016.

Resolução CNE/CP no 1, de 18 de fevereiro de 2002, institui Diretrizes Curriculares Nacionais para a Formação de Professores da Educação Básica. Disponível em: http://portal.mec.gov.br/seesp/arquivos/pdf/res1_2.pdf Acesso em: 19 jul. 2016.

Resolução n. 1, de 15 de maio de 2006. Institui Diretrizes Curriculares nacionais para o Curso de Pedagogia, licenciatura. MEC/ CNE. Diário Oficial da União. Brasília - DF, 16 mai. 2006 - Seção I-p 11.

Lei 12.796, de 04 de abril de 2013, que altera a Lei n. 9.394, de 20 de dezembro de 1996, que estabelece as Diretrizes e Bases da Educação Nacional, para dispor sobre a formação dos profissionais da Educação e dar outras providências. Disponível em: http://www.planalto.gov.br/ccivil_03/_ato20112014/2013/lei/l12796.htm Acesso em: 23 mar. 2017.

CORRÊA, G. T.; RIBEIRO, V. M. B. A formação pedagógica no ensino superior e o papel da pós-graduação Stricto Sensu. Educação e Pesquisa, São Paulo, v. 39, n. 2, p. 319-334, 2013

DINIZ-PEREIRA, J. E. Debates e pesquisas no Brasil sobre formação docente. In: DINIZ-PEREIRA, J.E. Formação de professores: pesquisas, representações e poder. 2. ed. Belo Horizonte: Autêntica, 2006, p. 15-52.

DINIZ-PEREIRA, J.C; LACERDA, M. P. Possíveis significados da pesquisa na prática docente: ideias para fomentar o debate. Educ. Soc., v. 30, n. 109, p. 1229-1242, 2009. 
GIROTO, C. R. M.; CASTRO, R.M. A formação de professores para a Educação Inclusiva: alguns aspectos de um trabalho colaborativo entre pesquisadores e professores da Educação Infantil, Rev. Educ. Espec., Santa Maria, v. 24, n. 41, p. 441-452, 2011 Disponível em:

ttps://periodicos.ufsm.br/educacaoespecial/article/view/3106/2701 Acesso em: 10 mar. 2017

LERNER, D.; SADOVSKY, P. O sistema de numeração: um problema didático. In:PARRA, C.; SAIZ, I. (Org.). Didática da matemática: Reflexões psicopedagógicas. Trad. Juan Acuña Llores. Porto Alegre: Artes Médicas, 1996, p. 73-108.

LÜDKE, M. A complexa relação entre o professor e a pesquisa. In: ANDRÉ, M. E.D. A. (Org). O papel da pesquisa na formação e na prática dos professores. 2. ed. São Paulo: Papirus, 2002.

Desafios para a pesquisa em formação de professores. Rev. Diálogo Educacional, Curitiba, v. 12, n. 37, p. 629-646, 2012

LÜDKE, M.; CRUZ, G. B. Aproximando Universidade e Escola de Educação Básica pela Pesquisa. Cadernos de Pesquisa, v. 35, n. 125, p. 81-109, 2005.

PENITENTE, L. A. A. Professores e pesquisa: da formação ao trabalho docente: uma tessitura possível. Formação Docente, Belo Horizonte, v. 04, n. 07, p. 19-38, 2012. Disponível em http://formacaodocente.autenticaeditora.com.br

PESCE, M. R.; ANDRÉ, M. E. D.A. Formação do professor pesquisador na perspectiva do professor formador. Formação Docente, Belo Horizonte, v. 04, n. 07, p. 39-50, 2012. Disponível em:

http://formacaodocente.autenticaeditora.com.br

RIBEIRO, M. M. G.; GUEDES, N. C. Fragmentos de histórias sobre ser docente: uma abordagem histórico-crítica de pesquisa. In: IBIAPINA, I. M. L. M.; RIBEIRO, M. M. G.; FERREIRA, M. S. Pesquisa em Educação - Múltiplos olhares. Brasília: Liber Livro, 2007, p. 97-117.

ROSA, S. S.; CARDIERI, E.; TAURINO, M. S. Pesquisa e formação de professores: reflexões sobre a iniciação à pesquisa no curso de pedagogia. Disponível em: http://www.anped.org.br/reunioes/31ra/1trabalho/GT08-4717. Acesso em: 22 out. de 2008. ensino e círculos acadêmicos. Cadernos de Pesquisa, Fundação Carlos Chagas, São Paulo, v. 35, n.125, p. 13-35, 2005. 
TEIXEIRA, L. A.; PASSOS, M. M.; ARRUDA, S. M. A formação de pesquisadores em grupo de pesquisa em Educação em Ciências e Matemática. Ciênc. Educ., v. 21, n. 2, p. 525-541, 2015.

UNESP. Projeto Político-Pedagógico do Curso de Pedagogia. Disponível em: http://www.marilia.unesp.br/Home/Graduacao/Pedagogia/projeto_pedagogico. pdf Acesso em: 12 mar. 2016

Recebido: 2017-04-19

Aprovado: 2017-10-29

DOI: $10.3895 /$ rbect.v11n1.5814

Como citar: PENITENTE, L. A. A.; GIROTO, C. R. M.; SOUZA, A. B. Entre o discurso e a prática: o lugar da pesquisa na formação de professores. Revista Brasileira de Ensino de Ciência e Tecnologia, v. 11, n. 1, 2018. Disponível em:

<https://periodicos.utfpr.edu.br/rbect/article/view/5814>. Acesso em: xxx.

Correspondência: Luciana Aparecida de Araujo Penitente - lucianapenitente@gmail.com Direito autoral: Este artigo está licenciado sob os termos da Licença Creative CommonsAtribuição 4.0 Internacional.

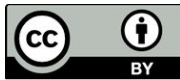

